Authors' final manuscript accepted for publication in Computers in Human Behavior, Please cite as: Rauschnabel, P.A., Rossmann, A. \& tom Dieck, M.C. (2017). An adoption framework for mobile augmented reality games: The case of Pokémon Go, Computers in Human Behavior.

\title{
An adoption framework for mobile augmented reality games: \\ The case of Pokémon Go
}

\begin{abstract}
Pokémon Go was the first mobile augmented reality (AR) game to reach the top of the download charts of mobile applications. However, little is known about this new generation of mobile online AR games. Existing theories provide limited applicability for user understanding. Against this background, this research provides a framework based on uses and gratification theory, technology risk research, and flow theory. The proposed framework aims to explain the drivers of attitudinal and intentional reactions, such as continuance in gaming or willingness to invest money in in-app purchases. A survey among 642 Pokémon Go players provides insights into the psychological drivers of mobile AR games. The results show that hedonic, emotional, and social benefits and social norms drive consumer reactions while physical risks (but not data privacy risks) hinder consumer reactions. However, the importance of these drivers differs depending on the form of user behavior.
\end{abstract}

Keywords: mobile gaming, augmented reality, Pokémon Go, gratification, risk, flow 


\section{Introduction}

One day, we believe this kind of immersive, augmented reality will become a part of daily life for billions of people.

—Mark Zuckerberg, Founder and CEO of Facebook Inc.

During the past few years, mobile technologies have diffused into all consumer segments (Salehan \& Negahban, 2013). Furthermore, technologies have converged from devices for particular tasks (e.g., a cellphone for phone calls, a Gameboy for gaming, a personal digital assistant for organization) to single devices. Current immersive technologies and apps aim to link the real world with the virtual world (Rauschnabel, Brem, \& Ivens, 2015). For example, users can take photos and upload them instantly on Instagram, tag friends on Facebook, or meet real-life partners on Tinder. Recently, augmented reality (AR) apps for mobile devices have entered consumer markets. Broadly speaking, AR is the name of a type of media in which digital information is integrated realistically in the physical world (Javornik, 2016).

AR provides opportunities for various industries, including those that develop interactive and engrossing games (Javornik, 2016). For example, Goldman Sachs (2016, p 4) documents that AR has the potential to "become the next big computing platform, and as we saw with the PC and smartphone, we expect new markets to be created and existing markets to be disrupted". Without a doubt, one of these new and maybe even disruptive markets is AR gaming. Recent AR game launches, such as Pokémon Go in 2016, have brought worldwide interest in the opportunities these types of games offer. Briefly, in Pokémon Go, players are asked to locate and catch virtual creatures hidden in real-world locations with their smartphones or other mobile devices. Media have called Pokémon Go "the biggest mobile game in U.S. history" (Lovelace, 2016). Wong 
(2017) and Zach and Tussyadiah (2017) propose that Pokémon Go will have huge implications for both consumers and companies (such as new marketing opportunities), and thus further research is required to investigate the behavioral consequences of playing Pokémon Go.

While AR games, such as Pokémon Go, are emerging, consumer research in this domain remains scarce (tom Dieck \& Jung, 2016). Most studies have focused primarily on the health sector and benefits of increased physical activity (Althoff, White, \& Horvitz, 2016; Baranowski, 2016; Ghosh \& Misra, 2016). However, not many frameworks that investigate why and how consumers play AR games are in current research. In addition, established theories are limited in applicability to AR games for several reasons. First, most existing technology or media adoption theories do not incorporate AR-specific factors. For example, AR games can be played outside and thus require physical activity of the player - such as catching Pokémon outside (Zach \& Tussyadiah, 2017). Second, mobile AR games are typically based on a freemium pricing model, which means downloading and playing the game for free, though users can buy additional features (so called 'in-app purchases') (Hamari et al., 2017). For example, downloading and playing Pokémon Go is for free, but users can buy certain features (e.g. Pokéballs) in an in-app store. Yet scant research has investigated this business model in related contexts. For example, gaming research commonly treats user evaluations of the games (e.g., attitudes) as a target construct. Managers might be interested in knowing whether a positive evaluation of a gaming experience also leads to more revenue or if other revenue drivers exist. Likewise, the scarce research on freemium pricing indicates drivers distinct from those commonly identified in the gaming literature (e.g., Hamari et al., 2017; Merikivi, Tuunainen, \& Nguyen, 2017). Thus, comparing the underlying psychological mechanisms that drive attitudes and different behaviors in one model contributes not only to the understanding of mobile AR games but also to the stream of freemium business models. Third, 
most existing theories neglect the risks consumers take in their decision-making. In particular, many studies argue that the existence of one or several gratifications drives usage behavior, but neglect the role of factors that decrease the intensity of use - risk factors. This research addresses these research gaps by concentrating on the following research questions: (1) What factors drive gamers' intention to play AR games? and (2) What factors drive in-app purchases?

To answer these questions, we propose a conceptual model grounded in the literature on media and technology acceptance and supplemented by prior research on gaming and AR. We test the model among 642 Pokémon Go players and analyze it using structural equation modeling (SEM). The findings offer several contributions to the literature. First, we show that various social, hedonic, and emotional factors drive gamers' attitudes toward playing the game. Second, we find that in-app purchases are driven by flow experience, the image of playing the game, and social norms but not by consumers' attitudes toward playing the game. These findings extend prior AR and gaming research with a novel framework and provide valuable insights for managers and game developers. Third, by using the context of Pokémon Go, this study provides a theoretically grounded explanation into the big hype of this app in 2016.

\section{Theoretical foundation}

\subsection{Mobile AR games}

\subsubsection{AR versus virtual reality}

Craig (2013, p.20) defines AR as a "medium in which digital information is overlaid on the physical world that is in both spatial and temporal registration with the physical world and that is interactive in time". Thus, a user can experience the real world "with virtual objects superimposed 
upon or composited with the real world" (Azuma 1997, p.356). For example, in Wikitude, one application that provides AR content users can use their smartphones to scan a famous building. Wikitude then automatically includes relevant Wikipedia information on the screen. Thus, in contrast with virtual reality, AR is not closed off from reality but melds the real and virtual worlds together (Javornik, 2016).

Research interest in AR has grown in the past five years, with scholars focusing on user adoption behavior (Rauschnabel et al., 2015, Rauschnabel 2017), marketing potential (Scholz \& Smith, 2016), and user requirements (tom Dieck, Jung, \& Han, 2016). In general, these studies conclude that novel and different factors drive consumer behavior (e.g., wearability, perceived augmentation etc), that single theories often fail to explain user behavior, and that different factors drive different usage patterns. In addition, research on mobile AR gaming in the consumer behavior context is still limited. Therefore, the current study takes into account prior research findings and established theories to address this research gap.

\subsubsection{Related Research}

Pokémon Go is one of the most popular AR games so far (Landi, 2016). In the game, players must catch and fight Pokémon while exploring and experiencing the real world (Dorward et al., 2017). As an AR application, Pokémon's virtual creatures appear on a user's device as if they are next to a user's real-world location. As the game progresses, players are able to train their Pokémon to become more powerful and fight against competing players (Dorward et al., 2016). Not surprisingly, when it first came out, public reaction to this game was intense and mixed (Lovelace, 2016). Supporters praised the potential to promote physical activity, while critics raised various fears, such as accidents, distractions while driving, nuisance, and threats to users' privacy (Sharma \& Vassiliou, 2016). For example, media and research reported road traffic accidents and muggings 
from users being distracted by the application (Lovelace, 2016; Sharma \& Vassiliou, 2016). Therefore, further research is required to evaluate user adoption of mobile AR games, the impact of such games on user behavior, and the core mechanisms of corresponding business models.

To the best of our knowledge, only few studies have investigated consumers' reactions to mobile AR games and Pokémon Go in particular. Zach and Tussyadiah (2017) explore the effects of Pokémon Go in the tourism context and find that players were willing to travel overnight to play the games, showing a newly identified potential of mobile AR gaming for the tourism industry. Players also confirmed a sense of community due to a connection with other players as well as a high degree of physical activity. Likewise, both Yang and Liu (2017) and Zsila et al (2017) investigated motivations for Pokémon Go use. These include Coping, Nostalgia, Escape, Competition, Fantasy, Boredom, Recreation and Outdoor Activity in Zsila et al (2017). The authors found correlates of these items with problematic gaming but not with impulsivity. Yang \& Liu (2017) identified Nostalgia, Exercise, Fun, Escapism, Friendship Maintenance, Relationship Initiation, and Achievement as motives. In a further series of correlation and regression analyses, they found correlates with personal well-being variables. A conceptual article by Keogh (2017) emphasizes the importance of Nostalgia as a success factor of Pokémon Go.

While these studies provide interesting findings on the role of Pokémon Go, and AR games in general, some unanswered questions remain. For example, while the aforementioned studies focus on the identification of motives, the focus of this study is on the relationship between gratifications, risks, norms, and different usage patterns (attitude, intention to use, and intention to spend money in in-app purchases). 


\subsubsection{Uses and gratification theory}

Grounded in communication science, uses and gratification theory (U\&GT) addresses the fundamental question of why people use particular media. U\&GT proposes that audiences are goal oriented and proactively select media that satisfy particular needs (Katz, Blumler, \& Gurevitch, 1973; Rubin, 2002). Although people's needs can vary depending on individual characteristics, they can be classified into five categories (Katz et al., 1973). The first category is cognitive needs, such as information gathering or increasing one's understanding of a particular issue. For example, people consume newspapers or watch news on television to gather particular information. The second category, social integrative needs, represents the idea that media can help people create new or maintain existing relationships through, for example, social media (Rossmann, Ranjan, \& Sugathan, 2016). Third, tension-release needs encompass aspects such as escapism or diversion. For example, people play games or watch movies to escape from everyday life. Fourth, affective needs include all forms of emotions, pleasure, and moods that people want to obtain. Fifth, personal integrative needs describe the idea that people engage in certain media to reaffirm their social status or to gain credibility among others. For example, some people use social media as a way to present themselves in a desired manner (e.g., as rich and successful) through a sort of image management (Karapanos, Teixeira, \& Gouveia, 2016).

U\&GT is not without its critics (Ruggiero, 2000), but it remains one of the most widely applied theories in human communication research (Rubin, 2002). One particular strength is its flexibility, which allows scholars to integrate it with other theories, such as technology acceptance theory (Shin, 2011) or flow theory (Huang, Hsieh, \& Wu, 2014). Therefore, we also incorporate constructs of these two theories in this research. Likewise, studies have applied and extended U\&GT to various contexts, such as digital photo sharing on social media (Malik, Dhir, \& 
Nieminen,2016) or mobile social games (Wei \& Lu, 2014). However, only a few studies have focused on the AR context and, in particular, AR gaming.

\section{Conceptual framework and hypotheses}

\subsection{Model overview}

As discussed previously, existing theories are unable to fully explain consumers' reactions to mobile AR games. Therefore, we propose an expanded model, which we present on a high level of abstraction in Fig. 1. According to the core idea of U\&GT, the model proposes that users' evaluation and perceptions of various benefits, risks, and social influences determine their reactions and intended behaviors.

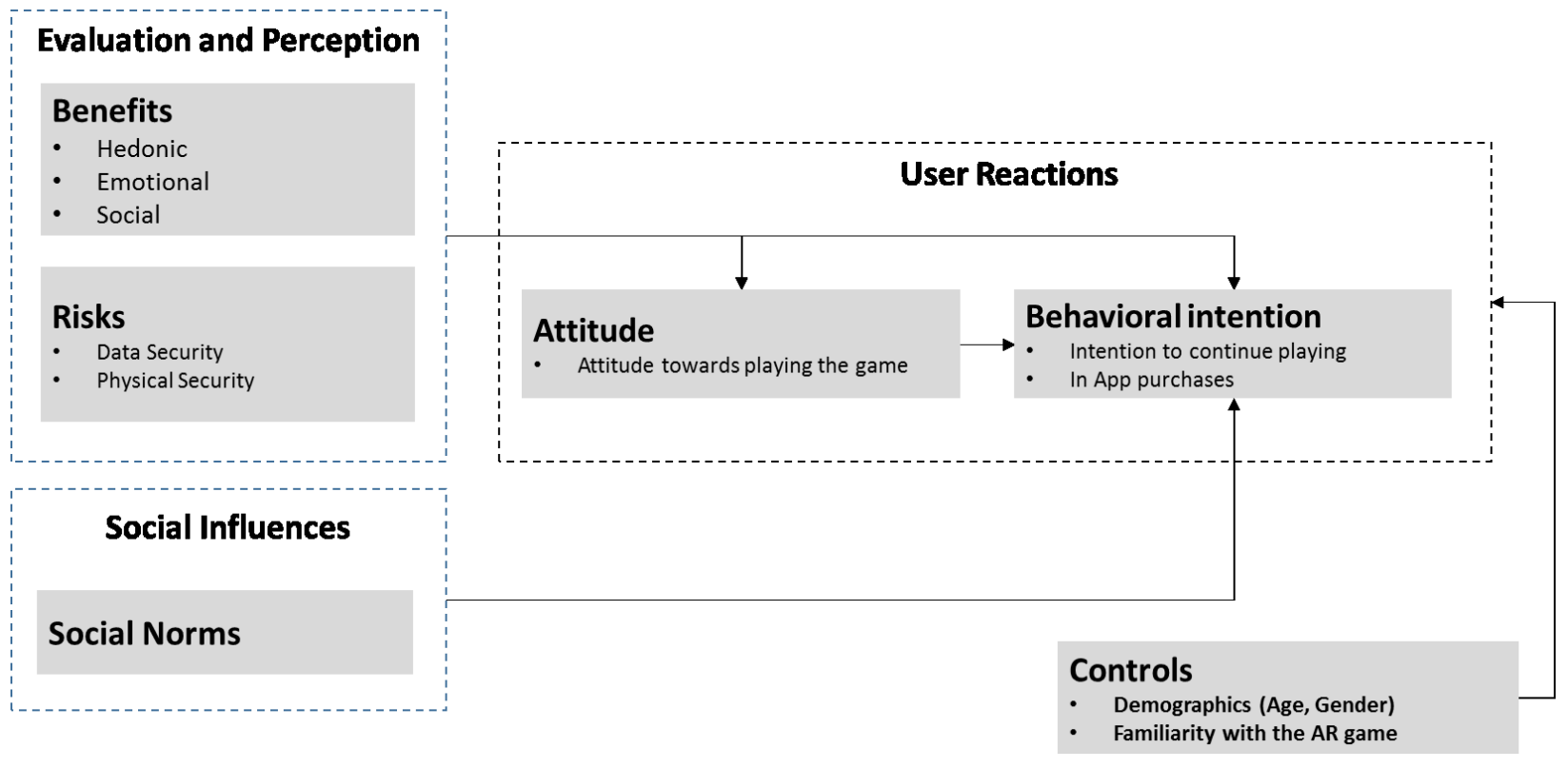

Fig. 1. Conceptual model (Overview)

U\&GT provides the foundation for the conceptualization of benefits in the proposed model. As discussed in the theory section on U\&GT, people use particular media to satisfy social integrative, personal integrative, tension-related, affective, and cognitive needs (Katz et al., 1973; Rubin, 
2002). As AR games are hedonic media visibly played in public, we propose that the first four needs are relevant for explaining relevant benefits (Rauschnabel et al., 2015; Rubin, 2002). Social and personal integrative needs are linked to benefits that derive from other people; in our model, we term this category of benefits (i.e., gratifications) as 'social benefits' covering specific constructs, such as image or the management of social relationships. Likewise, tension-related needs are linked to hedonic benefits and affective needs to emotional benefits.

\subsection{Benefits}

\subsubsection{Hedonic benefits}

We propose that three hedonic benefits—namely, enjoyment, physical activity, and flow—are relevant to understand user reactions and we outline why and how these factors determine consumers' acceptance of mobile AR games.

First, enjoyment is the degree to which users perceive playing mobile AR games as enjoyable. Many U\&GT and AR scholars have examined enjoyment and related hedonic gratifications and shown that these motivations drive game playing (Ha, Yoon, \& Choi, 2007, Wojciechowski \&Cellary, 2013). Similarly, Zsila et al (2017) show that people play Pokémon Go to reduce boredom and Yang \& Liu (2017) that gamers perceive it as fun. Building on these findings, we propose the following:

H1. Enjoyment has a positive effect on users' attitudes towards playing mobile AR games.

Second, scholars have begun recognizing the potential of AR applications to motivate consumers to engage in more outdoor activities (Althoff et al., 2016; Baranowski, 2016; Ghosh \& Misra, 2016; Wong, 2017; Zach \& Tussyadiah, 2017). Particularly in health literature, studies have shown 
the benefits of increased physical activity for improved health (Chittaro \& Sioni, 2012; Kendzierski \& DeCarlo, 1991; Penedo \& Dahn, 2005; Wong, 2017). Baranowski, Buday, Thompson, and Baranowski (2008, p.74) report that "video games provide extensive player involvement for large numbers of children and adults, and thereby provide a channel for delivering health behavior change experiences and messages in an engaging and entertaining format". Tripette (2016) suggest that the "game genre can become a fruitful collaboration between the health and fitness community and the gaming industry, with significant health benefit to the general public". In a similar vein, Howe et al. (2016) show positive short-term effects of playing Pokémon Go on users' level of physical activity, and both Yang and Liu (2017) and Zsila et al (2017) identified similar motivations for Pokémon Go use. While these studies discuss an increase of physical activity as a consequence of playing, we propose that this consequence serves as an expected gratification - in other words, an antecedent to AR game usage. Thus, the expected gratification from physical activity remains an under-researched area in U\&GT. This is not surprising, as most media and online games are played at home or on mobile devices that do not require a substantial amount of physical activity. Most people are aware that physical activity is good for them and feels good. Neuroscientists have identified two main reasons that physical exercise makes people feel better. On the one hand, human evolution has linked physical exercise to stress, such as hunting or fighting enemies. To cope with stress, the human brain releases the brain-derived neurotrophic factor, a protein that acts like a reset factor (Hopkins, Davis, VanTieghem, Whalen, \& Bucci, 2012). This protein works to make people feel 'at ease' and relaxed after intense exercise. On the other hand, physical activity often leads to the release of endorphins. These neuropeptides create a feeling of euphoria, also known as 'runner's high'. 
Scholars have shown that even low levels of physical activity can lead to significant improvements in psychological well-being and other positive outcomes (e.g., Berger \& Owen, 1998).

H2. Physical Activity has a positive effect on users' attitudes towards playing mobile AR games.

Third, Csikszentmihalyi (1975, p.36) explores the phenomenon of optimal experiences and thereby develops the core idea of flow theory, referring to flow as "the holistic experience that people feel when they act with total involvement". When people experience flow, they become absorbed in their activity in such a way that their awareness is narrowed to the activity itself. During flow, people feel in control of their environment, lose reflective self-consciousness, and perceive a distortion of temporal experiences that alters their subjective experience of time Csikszentmihalyi, 1975; Hsu \& Lu, 2004; Sundar \& Limperos, 2013; Webster, Trevino, \& Ryan, 1993). Finally, people usually perceive flow as something intrinsically rewarding (Csikszentmihalyi, 1975; Sundar \& Limperos, 2013). Therefore, flow is something that people typically evaluate as desired and thus is an influential construct in technology and media use (Webster et al., 1993).

Certain conditions need to be fulfilled for users to achieve a flow experience (Csikszentmihalyi, 1975; Schaffer, 2013). For example, users need to have a clear understanding of what and how to play an AR game. Help menus, intuitive designs, and guidance are ways most games address these two conditions. An additional condition is receiving feedback about one's performance while conducting a task. AR games usually present a user's scores or even high score lists. In situations in which navigation is required, Schaffer (2013) argues that knowing where to go is important, and AR apps are based on navigation to particular areas. For example, Pokémon Go includes arrows and maps that help users find their next clue. In addition, flow occurs when users are free from distractions (by definition, games help users escape from distractions (Sundar \& Limperos, 2013). 
Finally, flow requires a good balance between the task's challenges and the user's skills when performing a task (Csikszentmihalyi, 1975). In other words, performing a task that is too easy might lead to boredom, while a task that is too difficult might result in frustration. However, the optimum of challenges and skills is most likely to result in flow (Csikszentmihalyi, 1975).

Studies in marketing literature show increased consumer purchases when companies provide flow on their websites (Bridges \& Florsheim, 2008; Novak, Hoffman, \& Yung, 2004). As such, many studies have incorporated the flow construct into the technology and media adoption stream of research. For example, Hsu and Lu (2004) find that flow influences users' intention to play online games. Similarly, Huang, Backman, Backman, and Moore (2013) reveal that flow influences users' intention to visit places in Second Life, an online virtual world in which user' create their own avatars to interact with other users, places, and objects.

While these studies are examples of the widely replicated finding of the driving force of flow, we propose that flow is related to all three reaction variables in our model. Following Hsu and $\mathrm{Lu}$ 2004), we propose that flow has a positive effect on users' attitudes toward playing mobile AR games $(\mathrm{H} 3 \mathrm{a})$ and their intention to continue playing them $(\mathrm{H} 3 \mathrm{~b})$. In addition, we propose that flow drives in-app purchases $(\mathrm{H} 3 \mathrm{c})$ because such purchases help reduce the difficulty in a game. Prior research has shown that people are motivated to maintain the flow experience by proactively managing difficulty (Schaffer, 2013). Csikszentmihalyi (1975) notes that in situations in which challenges are too low, people increase flow by escalating the difficulty. In gaming, this means that gamers aim to reach a more difficult 'level'. In contrast, if challenges are too high, people can return to the flow state by learning new necessary skills. For example, gamers can ask other gamers for help or look up tricks on discussion boards. In many gaming apps with a freemium business model, users can also reduce challenges by buying certain in-game items they were not able to 
reach themselves. For example, in Pokémon Go users can purchase additional 'Pokéballs' or items to attract more Pokémon to their local area. Therefore, we propose that to maintain a flow experience, people tend to make in-app purchases.

H3a. Flow has a positive effect on users' attitudes toward playing mobile AR games.

H3b. Flow has a positive effect on users' intentions to continue playing mobile AR games.

H3c. Flow has a positive effect on users' intentions to make in-app purchases.

\subsubsection{Emotional benefits and the 'rosy view'}

Long-term knowledge about things is stored in consumers' associated networks (Fazio et al., 1986). For example, when people think about a particular brand (e.g., Apple), various associations (for example, a person might associate Apple with attributes such as fancy, well-designed, hip, or expensive) get activated or, in other words, emerge (Keller, 1993). These associations are highly subjective, and people use them to create an overall evaluation of an item. For example, if a person connects Apple with predominantly positive associations, he or she is likely to have a positive attitude toward the brand Apple.

Long-term knowledge is also biased in such a way that people tend to forget negative experiences and overrate positive experiences. For example, when people think about Christmas during their childhood, the white Christmas's or those in which they received unique gifts likely come immediately to mind. Mitchell, Thompson, Peterson, and Cronk (1997) term this effect as the 'rosy view'. In a similar vein, branding literature shows that many people value particular brands because of their link with certain traditions (e.g., Strizhakova, Coulter, \& Price, 2008).

We propose that playing games is something that most people began experiencing when they were children. Thus, playing a game might activate associations from the 'good old days' (Fazio et al., 
1986), which according to the rosy view are predominantly positive (Mitchell et al., 1997). Thus, our research model proposes that the more a game activates nostalgic associations, the more positive a consumer will react to it, which echoes prior research by Yang and Liu (2017) and Zsila et al (2017) who identified nostalgic association for Pokémon Go. So-called retro games (e.g., relaunches of Space Invaders, Tetris, and Leisure Suit Larry) also make use of nostalgia. While these retro games typically underperform newer games in terms of action, functionality, and graphics, they might particularly benefit from the rosy view. Thus:

H4. Nostalgia has a positive effect on users' attitudes toward playing mobile AR games.

\subsubsection{Social benefits}

U\&GT scholars have widely replicated the finding that social integrative motivations (i.e., the motivation to improve one's social relationships) are a fundamental driver of media choice and use (Ruggerio, 2000). For example, social media such as Facebook help people connect with other people (Rossmann et al., 2016; Sheldon, 2008), and smartphones and other mobile technologies provide the technological infrastructure to do so (Joo \& Sang, 2013). With regard to mobile AR games, we propose that social benefits, or the perceived benefits of creating new and maintaining existing social relationships through the use of a mobile AR app, drive acceptance of the app.

Playing AR games might help users get in touch with other gamers (Yang and Liu, 2017; Zsila et al., 2017). Many games have online communities — similar to brand communities — in which users discuss game-related and other topics (Muniz \& Schau, 2005). More important, playing mobile AR games is highly visible to others; for example, Pokémon Go users tend to look immersed in their smartphones' dark blue screen. Media has also reported on large groups of Pokémon Go users meeting in public places (e.g., 'hotspots' where the chances of catching Pokémon are high). If people with similar interests get in touch while engaging in similar activities (i.e., playing the same 
game), social interactions will likely occur, helping them form new relationships. In other words, playing the same game can serve as a 'conversation starter'.

People can also play mobile AR games with friends (Qin, Kim, Hus, \& Tan, 2011); in turn, spending time with friends might foster stronger relationships. As close relationships with friends are something people usually aim to attain with media (Katz et al., 1973; Rubin, 2002), we propose that this factor drives users' attitudes toward using Pokémon Go. Moreover, we propose that this effect is directly related to the intention to continue playing mobile AR games. This is because people often engage in activities not for the activity itself but for the ability to spend time with other people.

H5a. Socializing is positively related to users' attitudes toward playing mobile AR games.

H5b. Socializing is positively related to users' intention to continue playing mobile AR games.

We define image as the degree to which a user perceives that playing a mobile AR game will enhance his or her status in his or her social system (Moore \& Benbasat, 1991). We propose that if a user observes that a specific mobile AR game has a positive image among the public, he or she will believe that other people might attribute this image to him or her. Prior research has shown that people make use of consumption objects, technologies, and media to manage self-presentation (Strizhakova et al., 2008). Thus, we propose that image directly transfers to the three dependent variables. First, people tend to prefer things that have a good image (H6a). Second, even if people do not like something very much (e.g., a product), they might still prefer it to another product if it has a positive image (H6b). Finally, if a mobile AR game has a good image, people might use it more intensely (H6c). Thus: 
H6a. Image has a positive effect on users' attitudes toward playing mobile AR games.

H6b. Image has a positive effect on users' intentions to continue playing mobile AR games.

H6c. Image has a positive effect on users' intentions to make in-app purchases.

\subsection{Social norms}

We define social norms in our context as the degree to which a user believes that other people expect him or her to use a specific mobile AR game (Aijzen, 1985, Nolan et al., 2008). Theories on human decision making in general (e.g. Aijzen, 1985) but also with regards to technology (Hsu \& Lu, 2004) and media (Qin et al. 2011), and AR in particular (Rauschnabel \& Ro, 2016), have consistently revealed that norms are highly influential in predicting behavioral intentions. Thus, we propose that social norms drive both behavioral variables in our model:

H7a. Social norms have a positive effect on users' intentions to continue playing mobile AR games.

H7b. Social norms have a positive effect on users' intentions to make in-app purchases.

\subsection{Risks}

\subsubsection{Physical risk}

Physical risk involves the "potential threat to an individual's safety, physical health and wellbeing" (Lu, Hsu, \& Hsu, 2005, p.109). Mobile AR gaming is distinct in terms of fully immersing its users while being in the normal environment. Sharma and Vassiliou (2016) explore the effects of mobile AR gaming on people's lives and reveal serious road traffic accidents due to Pokémon Go. In addition, tom Dieck and Jung (2015) assess physical risks factors when using mobile AR applications and show that mugging is an important factor negatively affecting adoption behavior. Similarly, Luo, Zhang, and Shim (2010) propose a 'risk framework' and implement physical risk 
as a factor influencing technology adoption. We propose that both risk factors negatively affect consumers' reactions to mobile AR games. Thus:

H8. Physical risk has a negative effect on users' attitudes toward playing mobile AR games.

\subsubsection{Data privacy risks}

Information and media technology can pose threats to individual privacy, especially because users often pay for the use with personal information (e.g., Facebook) rather than with money (Collier, 1995). As media and technologies become increasingly personal and ubiquitous, concerns about privacy are also growing in importance (Ackerman, 2004). "In these highly personalized technological settings, talking about technology without considering the privacy implications, and vice versa, will be fruitless" (Junglas, Johnson, \& Spitzmüller, 2008, p.390). Against this background, many scholars conceptualize privacy concerns as a risk factor that reflects users' inherent worries about the possible loss of personal information from using a particular media or technology (Malhotra, Kim, \& Agarwal, 2004). Because a user's perception of a media's or technology's privacy issues reduces its perceived trustworthiness, privacy concerns are linked to a psychological barrier of risk involving vulnerability (Barney \& Hansen, 1994) and uncertainty (Lewis \& Weigert, 1985), two antecedents that decrease the adoption of media and technology (Connolly \& Bannister, 2007). Consequently, many studies have found that privacy and data security risks are directly linked to negative attitudes and intention behavior (Balta-Ozkan, Davidson, Bicket, \& Whitmarsh, 2013; Oliveira, Thomas, \& Espadanal, 2014). Thus:

H9. Privacy risk has a negative effect on users' attitudes toward playing mobile AR games. 


\subsection{Relationships between the endogenous variables}

We also propose that our independent variables are not independent of each other. In particular, we propose that a positive (vs. negative) attitude toward using mobile AR games leads to a higher (vs. lower) likelihood to use a game (King \& He, 2006). We also propose that people with more favorable attitudes are more willing to spend money for in-app purchases. Finally, we hypothesize that in-app purchases and intention to continue using a mobile AR game are interrelated. On the one hand, people who intend to play a game in the future might be more willing to invest money. On the other hand, people who have already invested money in in-app purchases likely have a higher intention to continue gaming because of these investments. Thus:

H10a. Users' positive attitudes toward mobile AR games have a positive effect on their intention to continue playing.

H10b. Users' positive attitudes toward mobile AR games have a positive effect on their intention to invest in in-app purchases.

H11. Users' intention to continue playing AR games is positively correlated with their intention to invest in in-app purchases.

\subsection{Control variables}

We also included three control variables in the model. To measure the extent of knowledge consumers have about mobile AR games, we included familiarity with the studied game (Pokémon Go) as a control variable. In addition, we included age and gender as two commonly used demographic variables. 


\section{Methodology and research design}

We applied survey methodology to analyze the proposed model. We chose Pokémon Go as the study context because it is one of the most prominent examples of mobile AR games, thus enabling us to survey a large sample of respondents. Another advantage of this approach is that it provides a theory-driven explanation of a well-known but under-researched phenomenon: 2016's Pokémon Go hype. In addition, the stated controversies of Pokémon Go in the media are likely to increase variance in many of the surveyed constructs (e.g., image, social norms).

\subsection{Data collection and sample}

With the help of a professional market research firm with an online panel, we surveyed 642 German respondents who reported having installed Pokémon Go on a mobile device. Respondents received financial compensation for participating. Table 1 presents the sample characteristics. The respondents received financial compensation for participation.

Table 1. Sample

\begin{tabular}{lll}
\hline Gender & & \\
& Male & $46.9 \%$ \\
& Female & $53.1 \%$ \\
Age & & \\
\hline & & \\
& 18-25 years & $6.4 \%$ \\
& 26-35 years & $34.6 \%$ \\
& 36 years or older & $46.0 \%$ \\
& Mean (SD) in years & $13.1 \%$ \\
\hline & & $27.4(6.3)$ \\
Job & Pupils & \\
Student & \\
Apprentice & $9.2 \%$ \\
Employed & $23.5 \%$ \\
Employed in a leading position & $4.0 \%$ \\
Self-employee / freelancer & $47.0 \%$ \\
Retired & $6.7 \%$ \\
Unemployed & $2.3 \%$ \\
Parental leave & $0.5 \%$ \\
Other/n.a. & $3.3 \%$ \\
& & $2.2 \%$ \\
& & $1.2 \%$
\end{tabular}


Frequency of Playing Pokémon Go

Daily (more than 30 minutes)

$12.6 \%$

Daily (less than 30 minutes)

$10.7 \%$

Several times a week

$26.5 \%$

Occasionally, but not every week

$28.2 \%$

Fewer

$22.0 \%$

$\mathrm{N}=642$; ${ }^{*}$ university/college level

\subsection{Measurement model and validation}

When possible, we adopted established scales to the research context (see appendix). We used seven-point Likert scales ( $1=$ totally disagree; $7=$ totally agree). We ran a series of exploratory and confirmatory factor analyses (CFAs) to assess and validate the psychometric characteristics of the hypothesized scales. The appendix provides an overview of the final measurement model's CFA. The overall CFA indicates good psychometric characteristics. In particular, although the overall model's chi-square was significant $\left(\chi^{2}=1371, \mathrm{df}=.624, p<.001\right)$, all other global fit measures were good $(\mathrm{CFI}=.972, \mathrm{NFI}=.966, \mathrm{RMSEA}=.043, \mathrm{SRMR}=.043)$. In addition, on a construct level, all composite reliability (CR), Cronbach's alpha, and average variance extracted (AVE) values exceeded the established minimums $(.7, .7$, and .5 , respectively; see appendix). Table 2 presents the construct correlations and descriptive statistics.

\section{Table 2}

Correlations and descriptive statistics.

\begin{tabular}{llllllllllllllll}
\hline & Mean & SD & 1 & 2 & 3 & 4 & 5 & 6 & 7 & 8 & 9 & 10 & 11 & 12 \\
\hline 1 & Familiarity & 5.34 & 1.43 & & & & & & & & & & & & \\
2 & Enjoyment & 4.97 & 1.34 & .57 & & & & & & & & & & \\
3 & Activity & 4.63 & 1.72 & .37 & .53 & & & & & & & & & \\
4 & Flow & 3.38 & 1.72 & .29 & .47 & .54 & & & & & & & & \\
5 & Nostalgia & 4.63 & 1.86 & .32 & .25 & .22 & .29 & & & & & & & \\
6 & Social norms & 3.07 & 1.57 & .23 & .34 & .45 & .65 & .29 & & & & & & \\
7 & Socializing & 3.41 & 1.61 & .27 & .44 & .62 & .65 & .31 & .77 & & & & & \\
8 & Image & 2.95 & 1.63 & .21 & .31 & .46 & .59 & .27 & .83 & .79 & & & & \\
9 & Privacy risks & 4.44 & 1.53 & -.08 & -.08 & .03 & -.02 & .01 & .02 & .07 & .00 & & & & \\
\hline
\end{tabular}




\begin{tabular}{llllllllllllllll}
\hline 10 & Physical risks & 4.55 & 1.57 & .01 & -.01 & .06 & .03 & .03 & -.05 & .04 & -.04 & .36 & & & \\
11 & Attitude toward using & 4.61 & 1.38 & .50 & .73 & .54 & .52 & .31 & .43 & .47 & .43 & -.11 & -.08 & & \\
12 & Intention to reuse & 3.63 & 1.78 & .44 & .59 & .50 & .55 & .30 & .53 & .53 & .52 & -.07 & -.05 & .78 & \\
13 & Invest in in-app purchases & 2.23 & 1.77 & .22 & .29 & .34 & .48 & .21 & .59 & .52 & .58 & -.01 & -.03 & .35 & .52 \\
\hline
\end{tabular}

Because we relied on self-reported data only, common method variance might be a threat to the validity of the findings. To assess this, we conducted a series of tests, including Harman's single-factor test and a marker variable test (Podsakoff, MacKenzie, Lee, \& Podsakoff, 2003). These procedures did not indicate any problems. In addition, we checked discriminant validity using Fornell and Larcker's (1981) recommended procedure. We therefore compared the squared correlations between all constructs with their AVEs. Among all pairs, squared correlations were lower than the AVEs of both constructs. Thus, problems with regard to discriminant validity are unlikely.

\section{Results}

Having established the measurement model, we next conducted SEM using the maximum likelihood estimator in Mplus 7.2 (Muthén \& Muthén, 2016). All fit measures were in line with the recommendations in the literature $\left(\chi^{2}=1556.25, \mathrm{df}=708, p<.001 ; \mathrm{CFI}=.968 ; \mathrm{NFI}=.963\right.$; RMSEA=.043; SRMR=.048). Fig. 2 illustrates all hypothesized and significant standardized path coefficients.

\subsection{Hypotheses testing}

We find that enjoyment $\left(\beta_{\mathrm{H} 1}=.52 ; p<.001\right)$, physical activity $\left(\beta_{\mathrm{H} 2}=.14 ; p<.01\right)$, flow $\left(\beta_{\mathrm{H} 3 \mathrm{a}}=.11\right.$; $p<.01)$, nostalgia $\left(\beta_{\mathrm{H} 4}=.08 ; p<.01\right)$, and image $\left(\beta_{\mathrm{H} 6 \mathrm{a}}=.15 ; p<.01\right)$ all drive users' attitudes toward playing Pokémon Go. In addition, higher levels of physical risk are related to lower attitudes toward playing Pokémon $\mathrm{Go}\left(\beta_{\mathrm{H} 8}=.06 ; p=.04\right)$. Thus, the results provide support for $\mathrm{H} 1, \mathrm{H} 2, \mathrm{H} 3 \mathrm{a}$, $\mathrm{H} 4$, H6a, and $\mathrm{H} 8$. We find no significant effects for socializing $\left(\beta_{\mathrm{H} 5 \mathrm{a}}=-.07 ; p=.27\right)$ and privacy 
risks $\left(\beta_{\mathrm{H} 9}=.04 ; p=.18\right)$, thus rejecting $\mathrm{H} 5 \mathrm{a}$ and $\mathrm{H} 9$. The control variables show significant effects on attitudes (familiarity with the game: $\beta=.07, p=.04$; age: $\beta=.08, p<.01$; gender: $\beta=.09, p<.01$ ). All these variables together explain $62.4 \%$ of the variance in attitudes toward playing Pokémon Go.

The model also identifies factors related to the intention to continue playing Pokémon Go. As hypothesized, users' attitudes toward using Pokémon Go $\left(\beta_{\mathrm{H} 10 \mathrm{a}}=.58 ; p<.001\right)$ are related to higher levels of continued use, in support of H10a. In addition, flow $\left(\beta_{\mathrm{H} 3 \mathrm{~b}}=.09 ; p=.02\right)$, image $\left(\beta_{\mathrm{H} 6 \mathrm{~b}}=.11\right.$; $p=.08)$, and social norms $\left(\beta_{\mathrm{H} 7 \mathrm{a}}=.11 ; p<.10\right)$ show (partially) significant effects, whereas we do not find this effect for social benefits $\left(\beta_{\mathrm{H} 5 \mathrm{~b}}=.01 ; p=.86\right)$. These results confirm H3b, H6b, and H7a but reject $\mathrm{H} 5 \mathrm{~b}$. The results are also weakly influenced by the control variables (familiarity with the game: $\beta=.08, p<.01$; age: $\beta=.16, p<.001$; gender: $\beta=.03, p=.33$ ). All these variables together explain $68.5 \%$ of the variance in intentions to continue playing Pokémon Go.

The results also provide insights into the factors that drive users' intention to invest in in-app purchases. This target construct is driven by flow $\left(\beta_{\mathrm{H} 3 \mathrm{c}}=.11 ; p=.02\right)$, image $\left(\beta_{\mathrm{H} 6 \mathrm{c}}=.25 ; p<.01\right)$, and social norms $\left(\beta_{\mathrm{H} 7 \mathrm{~b}}=.28 ; p<.01\right)$, in support of $\mathrm{H} 3 \mathrm{C}, \mathrm{H} 6 \mathrm{c}$, and H7b. Surprisingly, we find no significant effect for attitudes toward using Pokémon Go $\left(\beta_{\mathrm{H} 10 \mathrm{~b}}=.05 ; p=.30\right)$, rejecting H10b. In addition, the control variables weakly influence the in-app purchase variable (familiarity: $\beta=.05$, $p=.225$; age: $\beta=.08, p=.01$; gender: $\beta=.03, p=.33$ ). All these variables together explain $40.2 \%$ of the variance in consumers' intention to invest in in-app purchases.

Finally, we investigated the relationship between intention to continue using Pokémon Go and investment in in-app purchases. In support of H11, these two constructs are correlated $\left(r_{\mathrm{H} 11}=.24\right.$; $p<.001)$. 
Fig. 2. SEM results

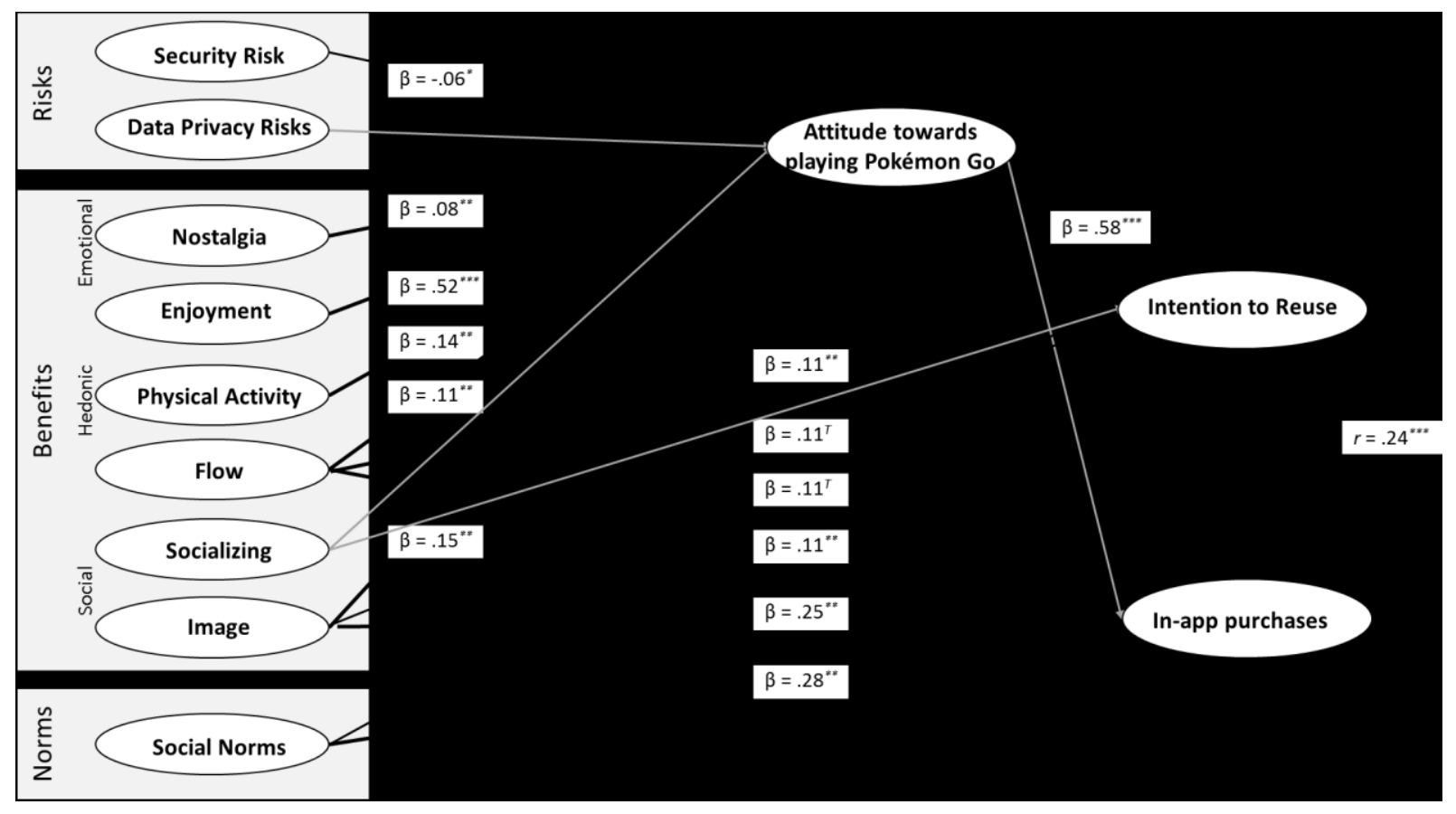

\subsection{Robustness test}

We conducted a series of robustness tests to assess the stability of the findings. First, we reanalyzed the data using different estimators. Second, we ran a saturated model in which we modeled all exogenous constructs on all endogenous constructs. Third, we re-analyzed the model without or with only select control variables to investigate potential mediating effects that might influence the results. All these robustness tests lead to similar results. Therefore, the results reported previously seem stable. In addition, we inspected the indirect effects of the exogenous variables on the intention to reuse constructs (mediated by the attitude). The indirect effects of those variables that were found to be significantly related $(\mathrm{p}<.05)$ to attitude were also significant and their 5\% confidence intervals (5000 bootstrap re-samples) did not include zero. Detailed results of the findings discussed in this section are available from the authors upon request. 


\section{Discussion}

Mobile AR games, such as Pokémon Go, have recently received attention. However, scant research has investigated how and why consumers use these games. To address this research gap, we developed a theoretical framework grounded in the literature on technology and media use and supplemented it with additional findings from related research streams by incorporating the characteristics of mobile AR games. We then tested the model in an empirical study using Pokémon Go as the example. The effects identified for the investigated benefits are in line with those reported in prior research from related applications (e.g., Hsu \& Lu, 2004; Qin et al., 2011; Sharma \& Vassiliou, 2016; Sheldon, 2008). In particular, we show that consumers' attitudes toward playing mobile AR games are mostly driven by the level of enjoyment they receive and the image that playing a particular game conveys to other people. In addition, nostalgia, the flow experience, and the physical activity from playing contribute to a positive association. However, the risk of being injured or hurt while playing decreases this attitude, confirming previous research in the mobile AR context (tom Dieck \& Jung, 2015). In addition, gamers' intention to continue playing is driven by their attitudes toward playing it and by the flow experience (Hsu \& Lu, 2004; Qin et al., 2011). Surprisingly, although playing mobile AR games is a highly social activity, socializing is not related to any of the target variables (Qin et al., 2011). A potential explanation is that consumers experience such a strong flow that they just do not value or make use of the socializing benefits that playing these games could offer.

Finally, we also investigate the intention to make in-app purchases, an under-researched but managerially relevant target in gaming research. Findings show that in-app purchases are driven by flow, image, and social norms, while attitudes toward playing the game are not a driver of inapp purchases. This counter-intuitive finding is surprising, as it means that spending money in in- 
app shops does not necessarily result in better attitudes toward the game. It also questions whether the overall evaluation of apps (e.g. on five-star rating) in app stores is a good indicator of app profitability.

\subsection{Theoretical contribution}

As the first major theoretical contribution of this study, we provide an extensive model of the factors that drive the acceptance and use of mobile AR games. The empirical study identifies several theoretical mechanisms that go beyond traditional technology and media use theories. For example, while most existing frameworks focus on single dependent variables, such as the intention to use (e.g., Venkatesh et al., 2012), our research provides a more nuanced understanding of the driving factors of different behaviors. For example, our model shows that the attitude toward using a mobile AR game is predominantly driven by gratifications obtained from playing the game, such as nostalgia and enjoyment. However, for in-app purchases, the model shows that this behavior is driven by flow, image, and social norms - more immersive and social factors.

The U\&GT literature on various gratifications suggests that gratifications are changing for new media, calling for the identification and assessment of novel ones (e.g., Papacharissi \& Mendelson 2011; Sundar \& Limperos, 2013). This study addresses this call by investigating two novel gratifications that have received limited attention in prior research: physical activity and nostalgia. While similar constructs have recently been discussed in the literature (Yang and Liu, 2017; Zsila et al., 2017), this study validates their relevance and shows how they explain different reactions of users. These gratifications can be applied in various future media and technology research endeavors to potentially explain the adoption of fitness trackers, activity games of gaming consoles, retro technologies or media (e.g., Gameboy), and so forth. In addition, while U\&GT is rooted in communication science, business scholars have applied it to contexts in which 
understanding of the drivers of financial target variables is crucial (Marchand \& Hennig-Thurau, 2013). In this study, we conceptualized and validated in-app purchases as a focal construct. Especially for apps with a freemium business model, understanding why users make in-app purchases could be highly relevant. Therefore, this research can also inspire researchers who study other forms media to investigate multiple facets of usage behavior, rather than just a general attitudinal or intentional dependent variable.

Finally, this study used the example of Pokémon Go as a study context. Therefore, on a contextual level, this study contributes to a better understanding of the Pokémon Go hype in 2016. In particular, considering the average score of the drivers, the results indicate that enjoyment $(\mathrm{M}=4.97)$, activity $(\mathrm{M}=4.63)$, and nostalgia $(\mathrm{M}=4.63)$ are significant drivers of the model, with relatively high values. Although flow shows a significant effect on all three variables, Pokémon Go seems not to be an app that creates particularly strong flow experiences $(M=3.38)$. Perhaps with more realistic AR technologies in the future, such as AR smart glasses (Rauschnabel \& Ro, 2016), flow might increase. Surprisingly, gamers seem to be aware of both privacy risks ( $M=4.44)$ and physical risks $(\mathrm{M}=4.55)$ but, as the results of the SEM indicate, only physical risks play a (minor) role.

\subsection{Limitations and future research}

As with any research, this study has some limitations. First, we conducted this study with users of mobile AR games. That is, we identified variations in the constructs among users but not nonusers. Therefore, the factors driving general interest in these games (i.e., whether people try these apps or not) remain an avenue for further research. Second, by focusing on Pokémon Go as a study context, this study increased the research relevance by examining the first popular mobile AR game, rather than a niche phenomenon. However, this research design, as well as its single-country 
focus, might limit the generalizability of the findings. For example, the magnitude of nostalgia might be higher for Pokémon Go than for games that do not incorporate characters from retro games. While many other retro games (e.g., Tamagotchi) might offer similar AR revivals, we also argue that any mobile AR game might activate nostalgic associations because they are played outside. In addition, as we theorized, any game that is played outside can activate childhood associations and the 'rosy view'. While in these cases the magnitude of the nostalgia construct might be lower, we assume that the effect will still hold. Additional research is necessary to verify this assumption, though caution should be taken when extrapolating the findings to other contexts.

While this research uses U\&GT as underlying theoretical framework, also other theories might be relevant for this and similar contexts. For example, Theory of Planned Behavior (Ajzen, 1985) and its extension, or technology acceptance theories (King \& He, 2006; Davies, 1989; Venkatesh et al., 2012) can provide valuable insights and other concepts, such as 'perceived behavioral control' (Ajzen, 1985), 'habit' (Venkatesh et al., 2012) or ease of use (Davies, 1989). Likewise, personality theories (e.g. Big Five, OCEAN) could provide an alternative theoretical lens by investigating relevant user characteristics, as shows in AR technologies (e.g. Rauschnabel et al., 2015) and other media (Correa at al., 2010; Seidman, 2013).

A novel variable in this research is the intention to invest in in-app purchases. Further research is necessary to better understand its drivers. In this research, we proposed that users make in-app purchases to manage flow by manipulating the complexity of the game. Thus, research could investigate this effect in more depth. Likewise, marketers might test whether investing money to attract players to popular areas around their businesses pays off or not. 


\section{Conclusion}

This study provides one of the first attempts to investigate the mechanisms that explain the popularity of mobile AR games. The findings show that this new form of gaming experience is driven by various hedonic, emotional, and social factors and social norms but limited by perceived physical risks. We hope that this research inspires future investigations in this promising and upcoming domain. 


\section{References}

Ackerman, M.S. (2004). Privacy in pervasive environments: Next generation labeling protocols. Personal and Ubiquitous Computing, 8(6), 430-439.

Ajzen, I. (1985). From intentions to actions: A theory of planned behavior. In Action control (pp. 11-39). Springer Berlin Heidelberg.

Althoff, Tim, Ryen W. White, and Eric Horvitz. "Influence of Pokémon Go on physical activity: Study and implications." Journal of Medical Internet Research 18.12 (2016).

Azuma, R.T. (1997). A survey of augmented reality. Presence: Teleoperators and Virtual Environments, 6(4), 355-385.

Balta-Ozkan, N., Davidson, R., Bicket, M., \& Whitmarsh, L. (2013). Social barriers to the adoption of smart homes. Energy Policy, 63, 363-374.

Baranowski, T. (2016). Pokémon Go, go, go, gone? Games for Health Journal, 5(5), 293-294.

Baranowski, T., Buday, R., Thompson, D. I., \& Baranowski, J. (2008). Playing for real: Video games and stories for health-related behavior change. American Journal of Preventive Medicine, 34(1), 74-82.

Barney, J.B., \& Hansen, M.H. (1994). Trustworthiness as a source of competitive advantage. Strategic Management Journal, 15(S1), 175-190.

Berger, B. G., \& Owen, D. R. (1998). Relation of low and moderate intensity exercise with acute mood change in college joggers. Perceptual and Motor Skills, 87(2), 611-621.

Bridges, E., \& Florsheim, R. (2008). Hedonic and utilitarian shopping goals: The online experience. Journal of Business Research, 61(4), 309-314.

Chittaro, L., \& Sioni, (2012). Turning the classic snake mobile game into a location-based exergame that encourages walking. In M. Bang \& E. L. Ragnemalm (Eds.), Persuasive technology. Design for health and safety (pp. 43-54). Berlin: Springer.

Collier, G. (1995). Information privacy. Information Management \& Computer Security, 3(1), 4145.

Connolly, R., \& Bannister, F. (2007). Consumer trust in Internet shopping in Ireland: Towards the development of a more effective trust measurement instrument. Journal of Information Technology, 22, 102-118.

Correa, T., Hinsley, A. W., \& De Zuniga, H. G. (2010). Who interacts on the Web?: The intersection of users' personality and social media use. Computers in Human Behavior, 26(2), 247-253.

Craig, A.B. (2013). Understanding augmented reality: Concepts and applications. Waltham, MA: Elsevier.

Csikszentmihalyi, M. (1975). Beyond boredom and anxiety: Experiencing flow in work and play. San Francisco: Jossey-Bass. 
Davis, F.D. (1989). Perceived usefulness, perceived ease of use, and user acceptance of information technology. MIS quarterly, 319-340.

Dorward, L.J., Mittermeier, J.C., Sandbrook, C., \& Spooner, F. (2017). Pokémon Go: Benefits, costs, and lessons for the conservation movement. Conservation Letters, 10(1), 160-165.

Fazio, R.H., Sanbonmatsu, D.M., Powell, M.C., \& Kardes, F.R. (1986). On the automatic activation of attitudes. Journal of Personality and Social Psychology, 50(2), 229-238.

Featherman, M.S., Miyazaki, A.D., \& Sprott, D.E. (2010). Reducing online privacy risk to facilitate e-service adoption: The influence of perceived ease of use and corporate credibility. Journal of Services Marketing, 24(3), 219-229.

Fornell, C., \& Larcker, D.F. (1981). Evaluating structural equation models with unobservable variables and measurement error. Journal of Marketing Research, 18(1), 39-50.

Ghosh, A., \& Misra, A. (2016). Pokémon Go, obesity and diabetes: A perspective from India. Diabetes Technology \& Therapeutics, 18(11), 725-726.

Goldman Sachs (2016) Virtual \& augmented reality. Retrieved March 31, 2016, from http://goldmansachs.com/our-thinking/pages/technology-driving-innovation-folder/virtualand-augmented-reality/report.pdf.

Ha, I., Yoon, Y., \& Choi, M. (2007). Determinants of adoption of mobile games under mobile broadband wireless access environment. Information \& Management, 44(3), 276-286.

Hamari, J., Alha, K., Järvelä, S., Kivikangas, J.M., Koivisto, J., \& Paavilainen, J. (2017). Why do players buy in-game content? An empirical study on concrete purchase motivations. Computers in Human Behavior, 68, 538-546.

Hopkins, M.E., Davis, F.C., VanTieghem, M.R., Whalen, P. J., \& Bucci, D.J. (2012). Differential effects of acute and regular physical exercise on cognition and affect. Neuroscience, 215, 5968 .

Howe, K.B., Suharlim, C., Ueda, P., Howe, D., Kawachi, I., \& Rimm, E.B. (2016). Gotta catch'em all! Pokémon GO and physical activity among young adults: Difference in differences study. $b m j, 355$, i6270.

Hsu, C.L., \& Lu, H.P. (2004). Why do people play on-line games? An extended TAM with social influences and flow experience. Information \& Management, 41(7), 853-868.

Huang, L.Y., Hsieh, Y.J., \& Wu, Y.C.J. (2014). Gratifications and social network service usage: The mediating role of online experience. Information \& Management, 51(6), 774-782.

Huang, Y.C., Backman, S.J., Backman, K.F., \& Moore, D. (2013). Exploring user acceptance of 3D virtual worlds in travel and tourism marketing. Tourism Management, 36, 490-501.

Javornik, A. (2016). Augmented reality: Research agenda for studying the impact of its media characteristics on consumer behaviour. Journal of Retailing and Consumer Services, 30, 252261. 
Joo, J., \& Sang, Y. (2013). Exploring Koreans' smartphone usage: An integrated model of the technology acceptance model and uses and gratifications theory. Computers in Human Behavior, 29(6), 2512-2518.

Junglas, I.A., Johnson, N.A., \& Spitzmüller, C. (2008). Personality traits and concern for privacy: an empirical study in the context of location-based services. European Journal of Information Systems, 17(4), 387-402.

Karapanos, E., Teixeira, P., \& Gouveia, R. (2016). Need fulfillment and experiences on social media: A case on Facebook and WhatsApp. Computers in Human Behavior, 55, 888-897.

Katz, E., Blumler, J.G., \& Gurevitch, M. (1973). Uses and gratifications research. Public Opinion Quarterly, 37(4), 509-523.

Keller, K.L. (1993). Conceptualizing, measuring, and managing customer-based brand equity. Journal of Marketing, 57(1), 1-22.

Kendzierski, D., \& DeCarlo, K. J. (1991). Physical activity enjoyment scale: Two validation studies. Journal of Sport \& Exercise Psychology, 13(1), 50-64.

King, W.R., \& He, J. (2006). A meta-analysis of the technology acceptance model. Information \& Management, 43(6), 740-755.

Landi, M. (2016) Pokemon Go app named as the most popular game of 2016 on Google Play, Mirror, 12/15/2016, retrieved from: http://www.mirror.co.uk/tech/pokemon-go-app-namedmost-9375173 $(7 / 17 / 2017)$

Lewis, J.D., \& Weigert, A. (1985). Trust as a social reality. Social Forces, 63(4), 967-985.

Lovelace, B. (2016), 'Pokemon Go' now the biggest mobile game in US history, CNBC. Retrieved January 10,2017, from $\mathrm{http} / / / \mathrm{www} . \mathrm{cnbc} . c 0 m / 2016 / 07 / 13 /$ pokemon-go-now-the-biggestmobile-game-in-us-history.html.

Lu, H.P., Hsu, C.L., \& Hsu, H.Y. (2005). An empirical study of the effect of perceived risk upon intention to use online applications. Information Management \& Computer Security, 13(2), 106120.

Luo, X., Li, H., Zhang, J., \& Shim, J. P. (2010). Examining multi-dimensional trust and multifaceted risk in initial acceptance of emerging technologies: An empirical study of mobile banking services. Decision Support Systems, 49(2), 222-234.

Malhotra, N.K., Kim, S., \& Agarwal, J. (2004). Internet users' information privacy concerns (IUIPC): The construct, the scale, and a causal model. Information Systems Research, 15(4), 336-355.

Malik, A., Dhir, A., \& Nieminen, M. (2016). Uses and gratifications of digital photo sharing on Facebook. Telematics and Informatics, 33(1), 129-138.

Marchand, A., \& Hennig-Thurau, T. (2013). Value creation in the video game industry: Industry economics, consumer benefits, and research opportunities. Journal of Interactive Marketing, 27(3), 141-157. 
Merikivi, J., Tuunainen, V., \& Nguyen, D. (2017). What makes continued mobile gaming enjoyable?. Computers in Human Behavior, 68, 411-421.

Mitchell, T.R., Thompson, L., Peterson, E., \& Cronk, R. (1997). Temporal adjustments in the evaluation of events: The "rosy view". Journal of Experimental Social Psychology, 33(4), 421448.

Moore, G.C., \& Benbasat, I. (1991). Development of an instrument to measure the perceptions of adopting an information technology innovation. Information Systems Research, 2(3), 192-222

Muniz, A.M., \& Schau, H. J. (2005). Religiosity in the abandoned Apple Newton brand community. Journal of Consumer Research, 31(4), 737-747.

Muthén, L.K., \& Muthén, B.O. (2016). Mplus: Statistical analysis with latent variables [Software]. Los Angeles: Muthén \& Muthén.

Nolan, J. M., Schultz, P. W., Cialdini, R. B., Goldstein, N. J., \& Griskevicius, V. (2008). Normative social influence is underdetected. Personality and Social Psychology Bulletin, 34(7), 913-923.

Novak, T.P., Hoffman, D.L., \& Yung, Y.F. (2000). Measuring the customer experience in online environments: A structural modeling approach. Marketing Science, 19(1), 22-42.

Oliveira, T., Thomas, M., \& Espadanal, M. (2014). Assessing the determinants of cloud computing adoption: An analysis of the manufacturing and services sectors. Information \& Management, 51(5), 497-510.

Penedo, F.J., \& Dahn, J.R. (2005). Exercise and well-being: a review of mental and physical health benefits associated with physical activity. Current Opinion in Psychiatry, 18(2), 189-193.

Podsakoff, P.M., MacKenzie, S.B., Lee, J.Y., \& Podsakoff, N.P. (2003). Common method biases in behavioral research: a critical review of the literature and recommended remedies. Journal of Applied Psychology, 88(5), 879.

Qin, L., Kim, Y., Hsu, J., \& Tan, X. (2011). The effects of social influence on user acceptance of online social networks. International Journal of Human-Computer Interaction, 27(9), 885-899.

Rauschnabel, P.A., Brem, A., \& Ivens, B.S. (2015). Who will buy smart glasses? Empirical results of two pre-market-entry studies on the role of personality in individual awareness and intended adoption of Google Glass wearables. Computers in Human Behavior, 49, 635-647.

Rauschnabel, P.A., \& Ro, Y.K. (2016). Augmented reality smart glasses: An investigation of technology acceptance drivers. International Journal of Technology Marketing, 11(2), 123148.

Rossmann, A., Ranjan, K.R., \& Sugathan, P. (2016). Drivers of user engagement in eWoM communication. Journal of Services Marketing, 30, 541-553 
Rubin, A.M. (2002). The uses-and-gratifications perspective of media effects. Hillsdale, NJ: Erlbaum.

Ruggiero, T.E. (2000). Uses and gratifications theory in the $21^{\text {st }}$ century. Mass Communication and Society, 3(1), 3-37.

Salehan, M., \& Negahban, A. (2013). Social networking on smartphones: When mobile phones become addictive. Computers in Human Behavior, 29(6), 2632-2639.

Schaffer, O. (2013), Crafting fun user experiences: A method to facilitate flow. White paper, Human Factors International

Scholz, J., \& Smith, A.N. (2016). Augmented reality: Designing immersive experiences that maximize consumer engagement. Business Horizons, 59(2), 149-161.

Seidman, G. (2013). Self-presentation and belonging on Facebook: How personality influences social media use and motivations. Personality and Individual Differences, 54(3), 402-407.

Sharma, P., \& Vassiliou, V. (2016). Pokémon Go: Cardiovascular benefit or injury risk? Oxford Medical Case Reports, 10.

Sheldon, P. (2008). Student favorite: Facebook and motives for its use. Southwestern Mass Communication Journal, 23(2), 39-53.

Shin, D. H. (2011). Understanding e-book users: Uses and gratification expectancy model. New Media \& Society, 13(2), 260-278.

Strizhakova, Y., Coulter, R.A., \& Price, L L. (2008). The meanings of branded products: A crossnational scale development and meaning assessment. International Journal of Research in Marketing, 25(2), 82-93.

Sundar, S.S., \& Limperos, A.M. (2013). Uses and grats 2.0: New gratifications for new media. Journal of Broadcasting \& Electronic Media, 57(4), 504-525.

tom Dieck, M.C., \& Jung, T. (2015). A theoretical model of mobile augmented reality acceptance in urban heritage tourism. Current Issues in Tourism, doi/full/10.1080/13683500.2015.1070801.

tom Dieck, M.C., \& Jung, T. (2016). Augmented reality gamification to enhance school children's learning experience in cultural heritage sites. Paper presented at EuroCHRIE Conference, Budapest (October 26-28).

tom Dieck, M.C., Jung, T. \& Han, D.I. (2016). Mapping requirements for the wearable smart glasses augmented reality museum application. Journal of Hospitality and Tourism Technology, $7(3), 230-253$.

Tripette, J. (2016). Pokemon-GO: recent learnings and suggestions for a more active gameplay. bmj, 355. 
Venkatesh, V., Thong, J.Y., \& Xu, X. (2012). Consumer acceptance and use of information technology: extending the unified theory of acceptance and use of technology. MIS Quarterly, 36(1), 157-178.

Webster, J., Trevino, L.K., \& Ryan, L. (1993). The dimensionality and correlates of flow in human-computer interactions. Computers in Human Behavior, 9(4), 411-426.

Wei, P.S., \& Lu, H.P. (2014). Why do people play mobile social games? An examination of network externalities and of uses and gratifications. Internet Research, 24(3), 313-331.

Wojciechowski, R. \& Cellary, W. (2013). Evaluation of learners' attitude toward learning in ARIES augmented reality environments. Computers \& Education, 68, 570-585.

Wong, F.Y. (2017). Influence of Pokémon Go on physical activity levels of university players: A cross-sectional study. International Journal of Health Geographics, $16(1), 8$.

Zach, F.J., \& Tussyadiah, I.P. (2017). To catch them all-the (un) intended consequences of Pokémon GO on mobility, consumption, and wellbeing. In Information and Communication Technologies in Tourism 2017 (pp. 217-227). Vienna: Springer. 


\section{Appendix}

Measurement model and CFA results.

\section{Construct Measures}

Enjoyment $(\alpha=.909 ; \mathrm{CR}=.92 ; \mathrm{AVE}=.79)$

inspired by Venkatesh et al. (2012)

Playing Pokémon Go is entertaining.

Playing Pokémon Go is fun.

Playing Pokémon Go is exciting.

Activity $(\alpha=.954 ; \mathrm{CR}=.95 ; \mathrm{AVE}=.84)$

inspired by Kendzierski \& DeCarlo (1991)

While playing Pokémon Go I walk much more.

While playing Pokémon Go I spend more time outdoors.

While playing Pokémon Go I am more physically active.

Flow $(\alpha=.963 ; \mathrm{CR}=.96 ; \mathrm{AVE}=.90)$

inspired by Novak et al. (2000)

Please think about playing Pokémon Go now.

The word "flow" is used to describe a state of mind sometimes experienced by people who are deeply involved in an activity. For example, athletes often experience a state of 'flow' by being completely and totally immersed and captivated in it and do not get distracted by anything else around them. Similar experiences are reported by people from their work, gaming or other hobbies.

When in flow, time may seem to stand still and nothing else seems to matter. Flow may not last for a long time on any particular occasion, but it may come and go over time. Typically, flow is described as an enjoyable and pleasurable experience.

While playing Pokémon Go, I undergo a "flow".

Most of the times I play Pokémon Go, I experienced a kind of "flow".

When I play Pokémon Go, I often experience a "flow".

Nostalgia $(\alpha=.944 ; \mathrm{CR}=.95 ; \mathrm{AVE}=.82)$

ad hoc scale, validated in pilot study.

Pokémon GO reminds me of nice moments in my childhood/youth.

I was exposed to Pokémon in the past (e.g., through movies or games).

Pokémon Go arouses positive childhood memories.

While playing Pokémon Go, I feel like going back in time to my great youth.

Social Norms $(\alpha=.838 ; \mathrm{CR}=.84 ; \mathrm{AVE}=.72)$

inspired by Venkatesh et al. (2012)

People who influence my behavior think I should play Pokémon Go.

People whose opinions I value encourage me to play Pokémon Go.

Socializing $(\alpha=.911 ; \mathrm{CR}=.91 ; \mathrm{AVE}=.72)$

inspired by Strizhakova et al. (2008)

Playing Pokémon Go helps me to meet other people.

I feel a kind of 'bond' to other people who also play Pokémon Go.

Playing Pokémon Go helps me to make contacts with fellow Pokémon Go players.

Playing Pokémon Go allows me to spend time with close friends and relatives.

Image $(\alpha=.937 ; \mathrm{CR}=.94 ; \mathrm{AVE}=.88)$

inspired by Moore \& Benbasat (1991)

If other people see me playing Pokémon Go, this impacts my image positively.

Playing Pokémon Go improves my image. 
Privacy Risks $(\alpha=.897 ; \mathrm{CR}=.90 ; \mathrm{AVE}=.75)$

inspired by Featherman, Miyazaki, \& Sprott (2010)

Pokémon Go is collecting too many private information.

When using Pokémon Go, I will lose control over the privacy of my information.

When using Pokémon Go, I doubt that my information are securely stored/saved.

Physical Risks $(\alpha=.893 ; \mathrm{CR}=.86 ; \mathrm{AVE}=.67)$

ad hoc scale, validated in a pilot study

I fear that I recognize risks in the real world too late while playing Pokémon Go.

Pokémon Go distracts me from immediate danger around me.

One risk of playing Pokémon Go is being distracted.

Attitude towards using $(\alpha=.938 ; \mathrm{CR}=.94 ; \mathrm{AVE}=.84)$

inspired by Davis (1989)

It is a good idea to play Pokémon Go.

I like playing Pokémon Go.

I have a positive attitude towards playing Pokémon Go.

Intention to continue playing Pokémon Go $(\alpha=931 ; \mathrm{CR}=.94 ; \mathrm{AVE}=.83)$

adopted from Venkatesh et al. (2012)

I plan to play Pokémon Go in the future.

I will play Pokémon Go frequently in the future.

In the future, I will play Pokémon Go significantly more often than other online games.

Intention for In-app purchases $(\alpha=.976 ; \mathrm{CR}=.98 ; \mathrm{AVE}=.93)$

ad hoc scale, validated in a pilot study.

I am willing to pay for additional features in the Pokémon Go shop.

I am willing to pay for Poké Balls or other items.

I plan to exchange money for Pokécoins in order to buy items in the app.

Note: Items were pretested $(n=18)$, further details are available upon request. 